\title{
Investigation of Bamboo Grid Packing Properties Used in Cooling Tower
}

\author{
Li-Sheng Chen ${ }^{1,2}$, Ben-Hua Fei ${ }^{1,2}$, Xin-Xin Ma ${ }^{1,2}$, Ji-Ping Lu ${ }^{3}$ and Chang-Hua Fang ${ }^{1,2, *(D)}$ \\ 1 Department of Biomaterials, International Center for Bamboo and Rattan, Beijing 100102, China; \\ chenlisheng@icbr.ac.cn (L.-S.C.); feibenhua@icbr.ac.cn (B.-H.F.); maxx@icbr.ac.cn (X.-X.M.) \\ 2 SFA and Beijing Co-built Key Laboratory of Bamboo and Rattan Science \& Technology, State Forestry \\ Administration, Beijing 100102, China \\ 3 Hengda Bamboo Filler Limited Company, Yixing 214200, China; hdlwz@163.com \\ * Correspondence: cfang@icbr.ac.cn; Tel.: +86-010-84789786
}

Received: 1 November 2018; Accepted: 5 December 2018; Published: 7 December 2018

check for updates

\begin{abstract}
Due to its advantages of good heat-resistance, environmental-friendliness, and low cost, bamboo grid packing (BGP) has become a promising new type of cooling packing. It is being increasingly used in Chinese industrial cooling towers to replace cooling packings made of polyvinyl chloride, cement, and glass fiber reinforced plastic. However, mechanical properties and fungal resistance are a concern for all bamboo applications. In this study, the modulus of rupture (MOR), modulus of elasticity (MOE), density, crystallinity, and environment scanning electron microscope (ESEM) properties were compared between fresh BGPs and those that had been in service for nine years in the cooling towers. The results showed that the MOR, MOE, density, crystallinity, and the crystal size of the used BGPs decreased to some extent, but still met the requirements for normal use in a cooling tower. The ESEM observation showed that the used BGPs were not infected by fungi. The decrease in mechanical properties could be caused by the decrease of density, crystallinity, and the decomposition of the chemical components of bamboo, but not by fungal infection.
\end{abstract}

Keywords: bamboo grid packing; cooling packing; cooling tower; mechanical properties; fungi; bamboo

\section{Introduction}

Hyperbolic cooling towers are widely installed at power plants, steel mills, petroleum refineries, and petrochemical plants due to their high capacity for heat rejection and energy saving. Compared to package-type cooling towers, hyperbolic cooling towers are generally much larger in size and require much more cooling packing. Cooling packing is the core component of cooling towers, and is responsible for $60 \%-70 \%$ of the heat dissipation in the cooling tower [1-4]. The type of packing material has an important role, as it provides a large surface area for evaporative heat and mass transfer from hot water to the ambient air and increases the contact time between both the two [5]. Different materials such as polyvinyl chloride (PVC), cement, and glass fiber reinforced plastic have been used as cooling packing. Currently the most popular cooling packing is made of PVC, with a market share exceeding $70 \%$ in China [6]. However, the PVC packing industry is facing major challenges, such as diminishing availability of petrochemical resources, increases in their prices, and the residues of PVC in the environment beyond its functional life [7]. In China, there are many power plants, steel mills, petroleum refineries, and petrochemical plants, from which the discarded cooling packing could cause severe environmental pollution. Furthermore, PVC packing has a short service life and poor anti-fouling properties. Thus, researchers and entrepreneurs have been seeking environmentally-friendly and longer-serving alternatives to PVC. 
Recently, packing material made of bamboo has been put to use in several hyperbolic cooling towers in China [8]. Bamboo, as one of the fastest-growing and most versatile plants, grows widely across tropical and temperate zones with wet climate. It is a raw material with great economic importance that has been used since ancient times. Accounting for around $1 \%$ of the world's total forest area [9], there is a total area of 31.5 million hectares of bamboo, $60 \%$ of which are concentrated in rapidly developing countries, such as China, India, and Brazil [10]. Bamboo is also an invasive plant in some parts of the world [11], the expansion of which tends to reduce the biological diversity in local environment, affect the physico-chemical properties and microbial composition of soil, weaken the ecosystem function, and change the forest landscape [12]. However, due to the combination of advantages of fast growth, short life cycle, high mechanical strength, and low energy consumption [13], bamboo also has an outstanding natural potential for use as packing material, which may help control the expansion of bamboo forests, reduce greenhouse gas, and provide carbon sequestration. Compared to PVC packing, bamboo grid packing (BGP) also has certain advantages in temperature adaptability, anti-fouling properties [6,8], as well as a good cooling performance [14-17]. However, durability has always been a concern for any application of bamboo materials. The compromising of mechanical properties caused by continuous exposure to hot water flow in the cooling tower can be problematic. In addition, bamboo is vulnerable to fungal infection because of its richness in nutrients. Fungal infection could be fatal as it decreases the mechanical strength of bamboo and subsequently shortens the BGP's service life. The lack of research in this aspect hinders the development of BGP for industrial application.

To fill this gap, the mechanical properties, such as the modulus of rupture (MOR) and modulus of elasticity (MOE), of BGPs that had been used for nine years in cooling towers were investigated and compared to the properties of unused control samples. Density and crystallinity were also investigated, and samples were observed under environment scanning electron microscope (ESEM) to gain a better understanding of the changes in mechanical properties, as well as BGP's fungal resistance.

\section{Materials and Methods}

\subsection{Materials}

Raw materials were obtained from Moso bamboo (Phyllostachys edulis (Carrière) J.Houz) grown in Shaowu, Fujiian Province, China. Bamboo culms were cut into strips (1200 mm in longitudinal direction and $40 \mathrm{~mm}$ in tangential direction). Three holes with a diameter of $10 \mathrm{~mm}$ were made on the strips. Round bamboo sticks were inserted into the holes to connect the bamboo strips, as shown in Figure 1. The dimension of one piece of BGP was $1200 \mathrm{~mm} \times 600 \mathrm{~mm} \times 40 \mathrm{~mm}$, and the spacing between the bamboo strips was $50 \mathrm{~mm}$. BGP units were stacked to a height of $1.5 \mathrm{~m}$ in a hyperbolic cooling tower (Figure 1). Control samples were collected from the fresh BGP units.

Nine-year-old BGP units were collected from two hyperbolic cooling towers located respectively in Fujian and Shandong Province. The BGP collected from Fujian Province (FJBGP) was used in a hyperbolic cooling tower of a thermal power plant. The one collected from Shandong Province (SDBGP) was used in a hyperbolic cooling tower of a steel mill. In both cooling towers, the inlet water temperature was 45 to $50{ }^{\circ} \mathrm{C}$, and the water mass flux was around $6500 \mathrm{~kg} /\left(\mathrm{h}^{*} \mathrm{~m}^{2}\right)$. Prior to the experiment, all specimens were conditioned at $21 \pm 2{ }^{\circ} \mathrm{C}$, with relative humidity of $65 \pm 3 \%$, to reach the equilibrium moisture content (EMC). 


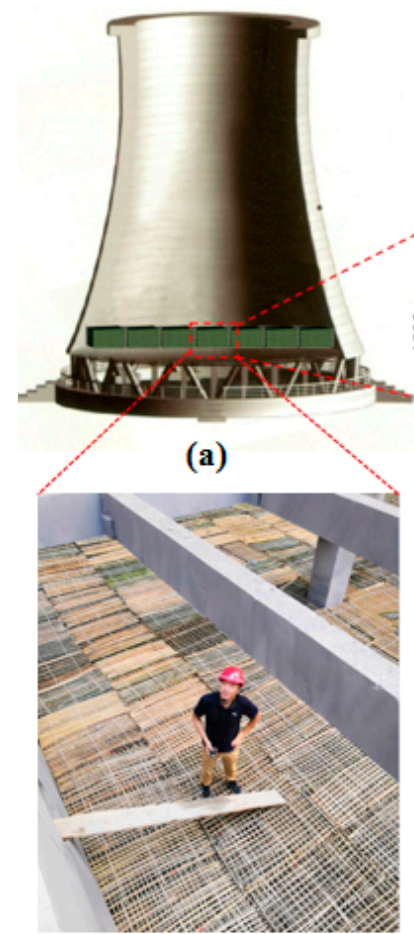

(d)

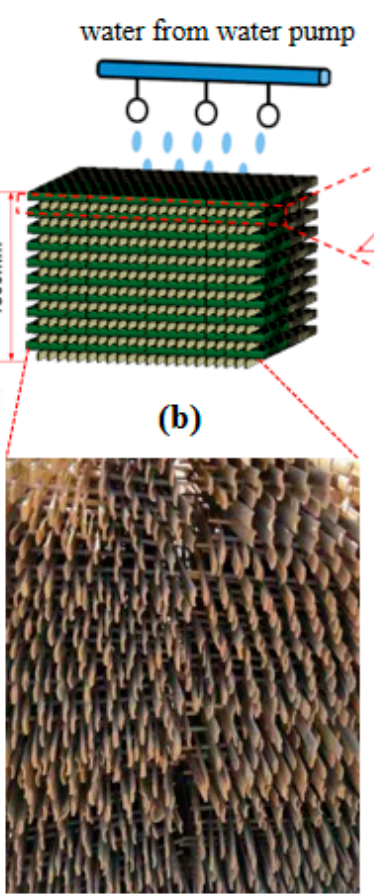

(e)



(c)

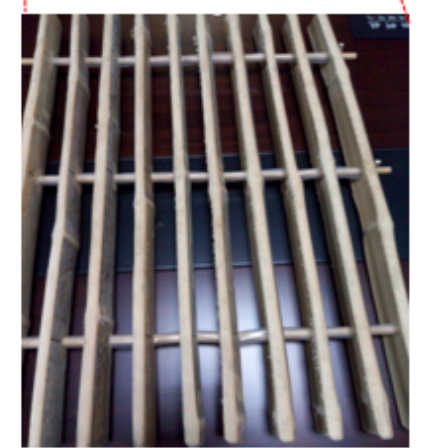

(f)

Figure 1. (a,d) Application of bamboo grid packing (BGP) in hyperbolic cooling towers; (b,e) stack of BGP units; (c,f) BGP assembled with bamboo strips.

\subsection{Mechanical Properties and Density Test}

Three-point static bending tests were performed according to GB/T 15780-1995 to obtain both the MOR and the MOE [18]. Since the load on the BGP is mainly in the tangential direction in the actual working environment of a cooling tower, the bending tests of bamboo strips were also performed in the tangential direction. The dimension of test specimens was $160 \mathrm{~mm}$ (longitudinal) $\times 10 \mathrm{~mm}$ (tangential) $\times \mathrm{t}$ (thickness of the bamboo culm wall). Tests were loaded along the tangential direction at a rate of $6 \mathrm{~mm} / \mathrm{min}$. The moisture content was measured after the bending tests. The specimen density was measured with the drainage method according to GB/T 1933-2009 [19]. The number of specimens in the control group, the FJBGP, and the SDBGP for the determination of mechanical properties and density testing were ten, twenty, and sixteen, respectively.

\subsection{Crystallinity Test}

Eighty mesh bamboo powder was used as the experimental material. Bamboo powder was processed by a mill, which comprised a means of randomly mixing and distributing the small fiber lengths in various directions at surface pressures far below those that would induce crystallite fracture [20]. X-ray diffraction (XRD) measurements were performed to assess the crystalline properties of air-dried bamboo cell walls using an X-ray diffractometer (AV300, Panalytical Co., Amsterdam, The Netherlands) at a wavelength of $0.154 \mathrm{~nm}$. The incident $X$-ray radiation was measured as the characteristic $\mathrm{Cu}$ X-ray passing through a nickel filter with a power of $40 \mathrm{kV}$ and $40 \mathrm{~mA}$. The XRD spectrum of every specimen was recorded in the angles $(2 \theta)$ of $5-50^{\circ}$. Three replicates were tested in this section. The cellulose crystallinity was calculated by the following Segal method [21]:

$$
C_{r I}=\frac{I_{002}-I_{a m}}{I_{002}} \times 100 \%
$$

where $C_{r I}$ represents the crystallinity of cellulose (\%), $I_{002}$ represents the reflection intensity of (002) plane diffraction, and $I_{a m}$ represents the intensity at the minimum near $18^{\circ}$ of $2 \theta$ angle. 
The Scherrer equation, in X-ray diffraction and crystallography, relates the size of sub-micrometer particles, or crystallites, in a solid to the broadening of a peak in a diffraction pattern [22]. This study used this method to determine the size of crystal particles in cellulose. The Scherrer equation was used to calculate the mean size of ordered (crystalline) domains and can be written as [23]:

$$
D=\frac{K \lambda}{\beta \cos \theta}
$$

where $D$ represents the mean size of the crystal region (nm), $K$ represents a dimensionless shape factor (0.9), $\lambda$ represents the $X$-ray wavelength, $\beta$ represents the line broadening at half the maximum intensity, and $\theta$ represents the scattering angle.

\subsection{Microstructure Observation}

An environmental scanning electron microscope (ESEM, XL30 FEG, FEI Co., Hillsboro, OR, USA) was used to observe the microstructure of bamboo strips. Cubic specimens ( $5 \mathrm{~mm} \times 5 \mathrm{~mm} \times 5 \mathrm{~mm})$ were carefully prepared with razor blades and microtome to obtain a neat surface. Then, the surfaces of specimens were coated with elemental gold film $(8-10 \mathrm{~nm})$ and observed under the ESEM.

\subsection{Statistical Analysis}

Multiple comparisons were first subjected to an analysis of variance (ANOVA) using SPSS 19.0 (IBM SPSS Corporation, Chicago, IL, USA), and significant differences between average values of control and used BGP specimens were determined using Duncan's test at 0.05 significance level.

\section{Results and Discussion}

\subsection{Mechanical Properties and Density}

The mechanical properties of the BGP strips are presented in Table 1. The MOR of FJBGP and SDBGP were 106.16 MPa and 107.91 MPa, respectively, and the MOE of FJBGP and SDBGP were 8869.66 MPa and 8986.50 MPa. The difference in mechanical properties between FJBGP and SDBGP was not statistically significant. However, the MOE and MOR of both FJBGP and SDBGP were all significantly lower than those of the control samples. These results demonstrated that the hygrothermal conditions in the cooling towers had a negative effect on the BGP's mechanical properties. This might be related to the degradation of bamboo components by the water flow, which decreased its density and crystallinity.

Table 1. The average MOR, MOE, and density of used BGPs and control samples.

\begin{tabular}{ccccccc}
\hline \multirow{2}{*}{ Materials } & $\begin{array}{c}\text { MOR } \\
(\mathbf{M P a})\end{array}$ & $\begin{array}{c}\text { MOE } \\
(\mathbf{M P a})\end{array}$ & \multicolumn{2}{c}{$\begin{array}{c}\text { Density } \\
\left(\mathbf{g} / \mathbf{c m}^{\mathbf{3}}\right)\end{array}$} & \multicolumn{2}{c}{ Retention of Properties (\%) } \\
\cline { 5 - 7 } & & & & MOR & MOE & Density \\
\hline Control & $143.15 \pm 16.68 \mathrm{a}$ & $10,250.83 \pm 1091.67 \mathrm{a}$ & $0.7165 \pm 0.4452 \mathrm{a}$ & 100 & 100 & 100 \\
FJBGP & $106.16 \pm 19.14 \mathrm{~b}$ & $8869.66 \pm 1737.26 \mathrm{~b}$ & $0.6596 \pm 0.5839 \mathrm{~b}$ & 74.16 & 86.53 & 92.06 \\
SDBGP & $107.91 \pm 26 \mathrm{~b}$ & $8986.50 \pm 2010.31 \mathrm{~b}$ & $0.6531 \pm 0.8499 \mathrm{~b}$ & 75.38 & 87.67 & 91.15 \\
\hline
\end{tabular}

Note: Standard deviation are presented after \pm . The different letters in the same column indicate a significant difference at the 0.05 level.

Compared to the control samples, the MOR retention of FJBGP and SDBGP were $74.16 \%$ and $75.38 \%$, respectively, and the MOE retention of FJBGP and SDBGP were $86.53 \%$ and $87.67 \%$. The retention of MOE exceeded that of MOR, which could be attributed to the fact that the hemicellulose and cellulose are more susceptible to degradation than lignin in hygrothermal condition [24,25]. Bamboo is mainly composed of cellulose, hemicellulose, and lignin. Cellulose in the cell walls of bamboo acts as a framework that provides both elasticity and strength, while lignin acts as a hard and solid substance that contributes to hardness and rigidity [26]. Hemicellulose acts as a matrix material 
that ensures the toughness, hardness, and strength of bamboo [24]. The thermal stability of lignin is better than that of cellulose and hemicellulose [26].

According to the "Technical specifications for bamboo filler of fossil fuel plants cooling tower" [27], the normal requirements for MOR and MOE are $100 \mathrm{MPa}$ and $8500 \mathrm{MPa}$, respectively. Although the mechanical properties of the used BGP decreased, they still met the requirements despite nine years of use.

The average densities and standard deviations are shown in Table 1. The difference in density between FJBGP and SDBGP was not statistically significant. The densities of FJBGP and SDBGPT were significantly lower than that of control samples at the 0.05 level. The density retention of FJBGP and SDBGP were $92.06 \%$ and $91.15 \%$, respectively, compared to control samples. The decrease of density could be explained by the degradation of bamboo cell wall components and the loss of water-soluble starch in the cell lumina (see Section 3.3) caused by the circulating hot water. However, the effect of starch loss on the density decrease could be neglected because the percentage of starch content in Moso bamboo is only around $0.1 \%$ [28]. The decrease of density could also explain the decrease of mechanical properties of the used BGP, since there was a significant correlation between density and mechanical properties, as presented in Figure 2, which was consistent with previous research [29]. However, the values of used BGPs were lower than those of control samples with similar densities for MORs (see the dotted circle of Figure 2), but not for MOEs. The reason could be the degradation and hydrolysis of hemicellulose and cellulose far exceeded that of lignin, as explained above. In addition, the decrease in cellulose crystallinity may also be an important factor (see Section 3.2).
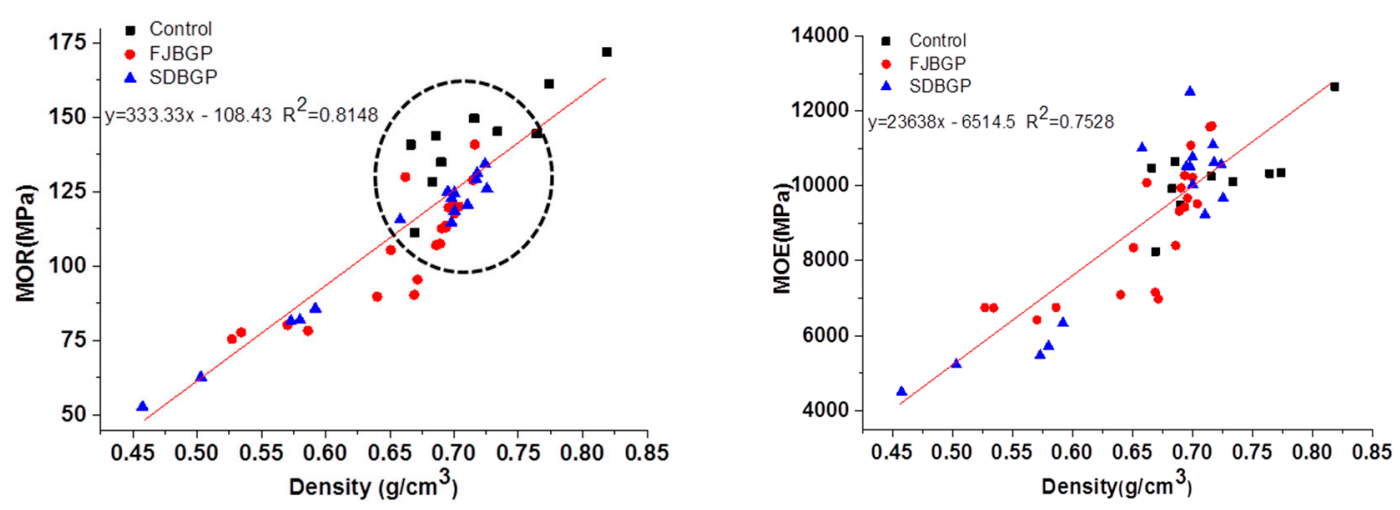

Figure 2. Relationships between MOR/MOE and density. Details of the dotted circles are explained in the text. FJBGP: bamboo grid packing collected from Fujian; SDBGP: bamboo grid packing collected from Shandong.

\subsection{Crystallinity}

Cellulose consists of amorphous and crystalline regions. Crystalline cellulose is tightly packed and hard to degrade, while the amorphous region easily decomposes under high temperature [30]. Cellulose crystallinity refers to the percentage of crystalline cellulose in the total cellulose and reflects the degree of crystallization that occurs during cellulose accumulation. The degree of orientation and relative content of the crystalline region have a significant effect on the fracture strength, toughness, and elastic modulus of bamboo [24]. When the cellulose is subjected to external forces, the molecular chains will be aligned along the direction of the external force to produce the preferential orientation, and the interaction between molecules will be greatly enhanced.

The XRD patterns of the three groups of samples are shown in Figure 3. It is clear that there was no change in the position of the cellulose diffraction peak. However, after BGP had been used in the cooling tower for nine years, the intensity of cellulose diffraction peak (002) significantly dropped. The crystallinity and crystal size of samples are as shown in Table 2. Compared to the control samples, the crystallinity retention of FJBGP and SDBGP were respectively $87.76 \%$ and $89.77 \%$, and the crystal size retention of FJBGP and SDBGP were $85.21 \%$ and $86.88 \%$. Hot water in the cooling tower could 
degrade the amorphous matrix of the used BGPs, which may increase the $C_{r I}$. However, in this study, the crystallinity of FHBGP and SDBGP decreased. This could be explained by the following reasons: The hot water cleaved acetyl groups from hemicellulose side chains to yield acetic and uronic acid [31], which catalyzed the hydrolysis of cellulose. Acid degraded not only the amorphous region of cellulose, but also the crystalline region [32], which is consistent with the decrease in crystal size (Table 2). The proportion of the crystalline region in the cell walls was low. When acid cleaved the molecular chain in the crystalline region, part of the crystalline region would be turned into an amorphous region, resulting in lower crystallinity and smaller crystal size of SDBGP and FJBGP.

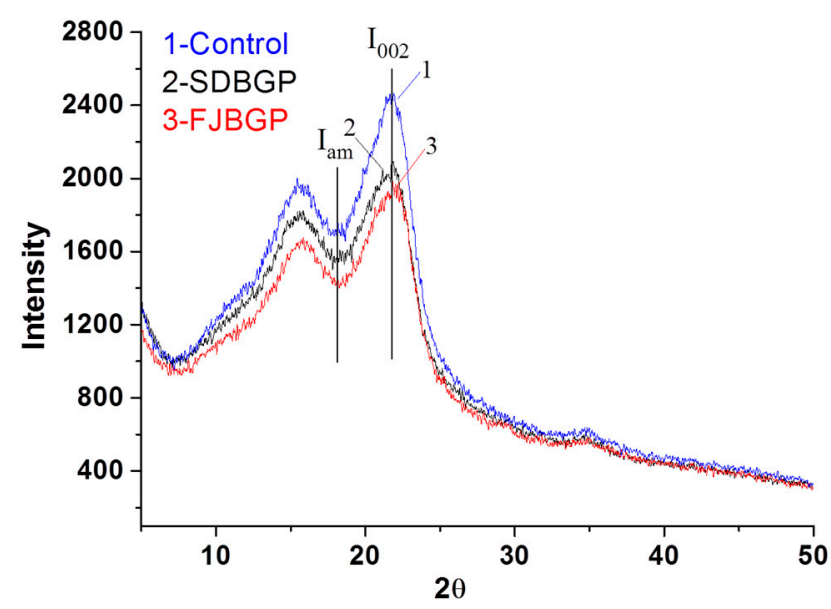

Figure 3. X-ray diffraction (XRD) patterns of the three sample groups.

Table 2. Crystallinity parameters of the three sample groups.

\begin{tabular}{cccccc}
\hline \multirow{2}{*}{ Sample } & \multirow{2}{*}{$\boldsymbol{\theta}$} & $\boldsymbol{C}_{\boldsymbol{r I}}$ & $\boldsymbol{D} \mathbf{( n m )}$ & \multicolumn{2}{c}{ Retention of Properties (\%) } \\
\cline { 5 - 6 } & & & & $\boldsymbol{C}_{\boldsymbol{r I}}$ & $\boldsymbol{D}$ \\
\hline Control & 21.88 & 0.3276 & 2.82 & 100 & 100 \\
FJBGP & 21.76 & 0.2875 & 2.4 & 87.76 & 85.21 \\
SDBGP & 21.83 & 0.2941 & 2.45 & 89.77 & 86.88 \\
\hline
\end{tabular}

The decrease in crystallinity led to low fracture strength and elastic modulus of the BGP, which can partly account for the decrease of MOR and MOE of used BGPs (Table 1).

\subsection{Microstructure Characteristics}

Bamboo is susceptible to insect and fungal infestation, which can modify the microstructure and reduce the mechanical properties of bamboo. According to the classification of durability, bamboo belongs to the third grade (non-durable grade). In general, when untreated bamboo is used in the outdoor environment, its service life does not exceed seven years [33]. The poor durability of bamboo is due to its richness in nutrients, which provide a food source for insects and rot fungi. After being infected by rot fungi, the microstructure of the bamboo changes, i.e., holes eroded by rot fungi appear in cell walls and mycelium in the cell cavities.

As shown in Figure 4a,b, the parenchyma cells of the control specimens contained many starch granules-several cells were virtually full of it. Furthermore, the starch granules were big. The inner walls of the cells were smooth. After being subjected to a rotting test for three weeks and 15 weeks, respectively, starch granules in the parenchyma cells disappeared and had been completely digested by rot fungi (Figure 4c,d) [33]. There were a large number of mycelia in the cell cavities, and the inner walls of the cells have formed big holes due to erosion by rot fungi. Noticeably, the following phenomena were observed in this study of both SDBGP and FJBGP: In the parenchyma cells of used BGPs, large-size starch granules disappeared (Figure 4e,f), but a few small-sized granules were still 
present. The inner walls of all cells remained smooth, without mycelium. The holes observed in the inner walls of cells were not the result of erosion by rot fungi, but were pits. These phenomena indicated that the BGPs were not attacked by fungi after being used for nine years, which could be explained by the following reasons: Firstly, the surfaces of the bamboo strips were covered with a 0.1-0.5 mm thick water film due to the continuous presence of water flow in the cooling tower [34]. Bamboo decay fungi are mostly aerobic fungi. The water film prevented them from obtaining oxygen. Secondly, the water temperature in the cooling towers generally exceeded $40^{\circ} \mathrm{C}$, which is higher than the suitable temperature for fungal growth $\left(3 \sim 38^{\circ} \mathrm{C}\right)$ [33]. Moreover, the starch granules in the bamboo were partially dissolved by the circulating hot water, resulting in the decreased amount and size.
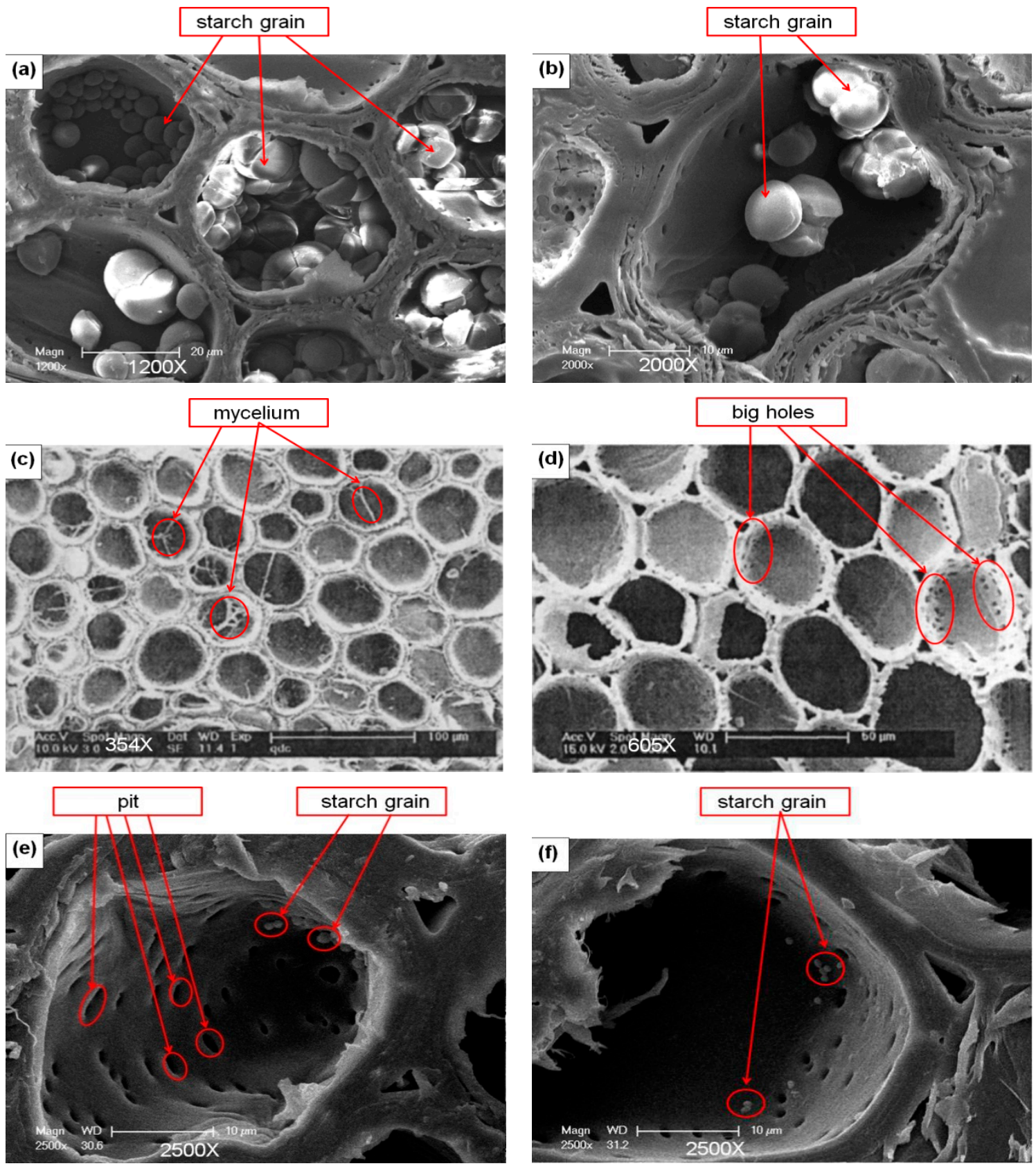

Figure 4. Environment scanning electron microscope (ESEM) images of bamboo cells. (a,b) Control samples; (c,d) specimens after three and 15 weeks of decay, respectively (from Qin [33]); (e,f) specimens of the used BGPs. 
Combining all the findings and analyses, it can be concluded that the decreases in the mechanical properties of used BGPs were caused by decreases in density and crystallinity instead of fungal infection, despite that, for most bamboo applications, reduced durability caused by fungal damage is one of the major problems.

\section{Conclusions}

The properties of BGP that had been in use for nine years in two industrial cooling towers were investigated and compared to those of unused control samples. It was found that the MOR and MOE retentions were around $75 \%$ and $87 \%$, respectively, which still met the normal use requirements for cooling towers. The density decreased with retention more than $91 \%$. The crystallinity and crystal size retentions were about $89 \%$ and $86 \%$, respectively. Bamboo is vulnerable to fungal infection due to its rich content of nutrients. However, a small amount of small-size starch granules was still present in the cell lumina of used BGP, and bamboo cell walls were also free from mycelia, which indicated that the used BGPs were not infected by fungi. No significant differences in the properties were found for the BGPs collected from the two cooling towers, which had similar conditions.

This study provides primary data for BGP used in industrial cooling towers. Further evaluation of BGP's service life is essential, as it may help promote the application of BGP as one of many uses of the abundant biomass resource of bamboo.

Author Contributions: L.-S.C., C.-H.F., and B.-H.F. conceived and designed the experiments; L.-S.C. performed the experiments; X.-X.M. analyzed the data; J.-P.L. contributed reagents/materials/analysis tools; L.-S.C. wrote the paper, and C.-H.F. revised it.

Funding: This research was funded by the Foundation of International Centre for Bamboo and Rattan (grant number: 1632016015) and the Forestry Patent Industrialization Guidance Project (grant number: Forestry Patent 2017-2).

Acknowledgments: The authors acknowledge the financial supports of the Foundation of International Centre for Bamboo and Rattan (No. 1632016015) and the Forestry Patent Industrialization Guidance Project (Forestry Patent 2017-2).

Conflicts of Interest: The authors declare no conflict of interest.

\section{References}

1. Zhao, Z.G. A New Thermo-characteristic Formula for the Packing of Cooling Tower and It's use. J. Hydrodyn. 1996, 11, 599-605.

2. Chen, J.B.; Wang, Y.H.; Wang, J.; Zhang, P.; De-Xing, L.I. Experimental study on performance of cooling tower packing. Ind. Water Wastewater 2010, 41, 65-68.

3. Goshayshi, H.R.; Missenden, J.F. The investigation of cooling tower packing in various arrangements. Appl. Therm. Eng. 2000, 20, 69-80. [CrossRef]

4. Chen, J.B.; Shi, Y.H.; Wang, Y.H.; Hou, H.L.; Li, D.X. Experimental Study of Cooling Tower Packing and Deduce the New Formula of the NTU. Adv. Mater. Res. 2012, 383-390, 6134-6138. [CrossRef]

5. Lemouari, M.; Boumaza, M. Experimental investigation of the performance characteristics of a counterflow wet cooling tower. Energy 2010, 36, 5815-5823. [CrossRef]

6. Ma, X.X.; Lu, J.P.; Qin, D.C.; Fei, B.H. Application of bamboo in the circulating water cooling system. J. For. Eng. 2016, 1, 33-37.

7. Fazita, M.R.N.; Jayaraman, K.; Bhattacharyya, D.; Haafiz, M.K.M.; Saurabh, C.K.; Hussin, M.H.; Abdul, K.H.P.S. Green Composites Made of Bamboo Fabric and Poly (Lactic) Acid for Packaging Applications-A Review. Materials 2016, 9, 435. [CrossRef] [PubMed]

8. Chen, Y.L.; Shi, Y.F.; Xie, D.X. Performance Comparison between Bamboo Grid Packing and PVC Film Packing and its Applications. Power Stn. Aux. Equip. 2016, 37, 37-41.

9. Lobovikov, M.; Paudel, S.; Piazza, M.; Ren, H.; Wu, J. World bamboo resources. A thematic study prepared in the framework of the Global Forest Resources Assessment 2005. Non-Wood For. Prod. 2007. [CrossRef]

10. Chirici, G.; Corona, P.; Portoghesi, L. Global forest resources assessment. Ital. J. For. Mt. Environ. 2013, 4, 269-273. 
11. Lima, R.A.F.; Rother, D.C.; Muler, A.E.; Lepsch, I.F.; Rodrigues, R.R. Bamboo overabundance alters forest structure and dynamics in the Atlantic Forest hotspot. Boil. Conserv. 2012, 147, 32-39. [CrossRef]

12. Yang, Q.P.; Yang, G.Y.; Song, Q.N.; Shi, J.M.; Ou, Y.M.; Qi, H.Y.; Fang, X.M. Ecological studies on bamboo expansion: Process, consequence and mechanism. Chin. J. Plant Ecol. 2015, 39, 110-124.

13. Fang, C.H.; Jiang, Z.H.; Sun, Z.J.; Liu, H.R.; Zhang, X.B.; Zhang, R.; Fei, B.H. An overview on bamboo culm flattening. Constr. Build. Mater. 2018, 171, 65-74. [CrossRef]

14. Xi, M.J.; Zhang, R.P.; Wang, X.G.; Li, N.; Lu, S.J.; Yu, Z.X. Analysis of Characteristic of Bamboo Grating Filler in Cooling Tower. Hebei Electr. Power 2000, 2, 42-43.

15. Chu, X.M.; Wu, Y.C. The Cooling Effect is Significant after Cooling Tower Replaces the Bamboo Grid Packing. Power Stn. Aux. Equip. 1996, 2, 22-23.

16. Wang, Z.Q.; Liang, Q.; Chen, X. Transformation \& economic analysis of cooling tower trickling filler in 300 MW unit. Ningxia Electr. Power 2005, 1, 42-46.

17. Fei, B.H.; Ma, X.X.; Qin, D.C.; Lu, J.P. New Materials for Industrial Cooling Tower: Bamboo Packing. World Bamboo Rattan 2016, 14, 31-35.

18. GB/T 15780-1995 Testing Methods for Physical and Mechanical Properties of Bamboos; General Administration of Quality Supervision, Inspection and Quarantine of the People's Republic of China/Standardization Administration of the People's Republic of China: Beijing, China, 1995.

19. GB/T 1933-2009 Method for Determination of the Density of Wood; General Administration of Quality Supervision, Inspection and Quarantine of the People's Republic of China/Standardization Administration of the People's Republic of China: Beijing, China, 2009.

20. Aeo, B.S.; Chaabouni, Y.; Msahli, S.; Sakli, F. Morphological and crystalline characterization of $\mathrm{NaOH}$ and $\mathrm{NaOCl}$ treated Agave americana L. fiber. Ind. Crops Prod. 2012, 36, 257.

21. Li, J. Wood Spectroscopy; Science Press: Beijing, China, 2003.

22. Patterson, A.L. The Scherrer Formula for X-ray Particle Size Determination. Phys Rev. 1939, 56, 978-982. [CrossRef]

23. Chen, M.; Wang, C.; Fei, B.; Ma, X.; Zhang, B.; Zhang, S.; Huang, A. Biological Degradation of Chinese Fir with Trametes Versicolor (L.) Lloyd. Materials 2017, 10, 834. [CrossRef]

24. Liu, Y.X.; Zhao, G.J. Wood Resources Materials Science; China Forestry Publishing House: Beijing, China, 2004.

25. Tjeerdsma, B.F.; Militz, H. Chemical changes in hydrothermal treated wood: FTIR analysis of combined hydrothermal and dry heat-treated wood. Holz Roh-Werkst 2005, 63, 102-111. [CrossRef]

26. Qin, L. Effect of Thermo-Treatment on Physical, Mechanical Properties and Durability of Reconstituted Bamboo Lumber; Chinese Academy of Forestry: Beijing, China, 2010.

27. DL/T 1361-2014 Technical Specifications for Bamboo Filler of Fossil Fuel Plants Cooling Tower; National Energy Administration of the People's Republic of China: Beijing, China, 2014.

28. Fan, F.Y. Seasonal Variation of Starch Content in Dendrocalamus giganteus and Phyllostachys edulis and Its Relationship to Insect Damages; Southwest Forestry University: Kunming, China, 2010.

29. Xu, Y.M. Wood Science; China Forestry Publishing House: Beijing, China, 2006.

30. Bhuiyan, M.T.R.; Hirai, N.; Sobue, N. Changes of crystallinity in wood cellulose by heat treatment under dried and moist conditions. J. Wood Sci. 2000, 46, 431-436. [CrossRef]

31. Sattler, C.; Labbé, N.; Harper, D.; Elder, T.; Rials, T. Effects of Hot Water Extraction on Physical and Chemical Characteristics of Oriented Strand Board (OSB) Wood Flakes. CLEAN-Soil Air Water 2010, 36, 674-681. [CrossRef]

32. Li, X.J.; Liu, Y.; Gao, J.M.; Wu, Y.Q.; Yi, S.L.; Wu, Z.P. Characteristics of FTIR and XRD for wood with high-temperature heating treatment. J. Beijing For. Univ. 2009, 31, 104-107.

33. Qin, D.C. A Fundamental Sudy on the Application of CuAz Preservatives for Bamboo; Chinese Academy of Forestry: Beijing, China, 2004.

34. Northwest Electric Power Design Institute. Power Engineering Water Design Manual; China Electric Power Press: Beijing, China, 2005.

(C) 2018 by the authors. Licensee MDPI, Basel, Switzerland. This article is an open access article distributed under the terms and conditions of the Creative Commons Attribution (CC BY) license (http:// creativecommons.org/licenses/by/4.0/). 